\title{
A Case of COVID-19 Infection Associated with Severe Cold Agglutinin Autoimmune Haemolytic Anaemia
}

\section{Prabhashini Kumarihamy ${ }^{1 *}$, Sujeewa Gunaratne ${ }^{1}$, Ashani Ratnayake ${ }^{2}$, Hiranya Abeysinghe ${ }^{1}$, Sahan Perera $^{1}$, Vishaka Rajapaksha ${ }^{3}$ and Navoda Wickramasinghe ${ }^{4}$}

${ }^{1}$ Consultant Physician, Base Hospital, Teldeniya, Sri Lanka

${ }^{2}$ Consultant Anaesthetist, Base Hospital, Teldeniya, Sri Lanka

${ }^{3}$ Consultant Haematologist, National Hospital, Kandy, Sri Lanka

${ }^{4}$ Research Assistant, Base Hospital, Teldeniya, Sri Lanka

*Corresponding author: Prabhashini Kumarihamy, Consultant physician, Base Hospital, Teldeniya, Sri Lanka

\begin{abstract}
Background: COVID-19 is known to cause systemic disease with multiple organ dysfunctions. COVID-19 associated immune-mediated phenomena such as autoimmune haemolytic anaemia has been identified previously with rare incidence. However, the association between COVID-19 infection and autoimmune haemolytic anaemia is not fully evaluated.

Case presentation: Here, we present a case of a previously well patient who developed severe cold agglutinin hemolytic anemia during the course of COVID-19 infection. Although there were no thrombotic complications, he developed acute kidney injury and COVID-19 lung involvement during the course of the disease. He was successfully treated with blood transfusion, oxygen therapy, corticosteroids and antibiotics and, best supportive care.

Conclusion: Although it is an uncommon presentation, clinicians need to be aware of COVID-19 infectionassociated autoimmune manifestations including warm and cold type haemolytic anaemia. This case emphasizes the importance of an extensive diagnostic workup to identify autoimmune haemolytic anaemia in COVID-19 patients who could present with severe anaemia which requires timely management to save their lives.
\end{abstract}

\section{Keywords}

COVID-19, Cold agglutinin, Autoimmune haemolytic anaemia

\section{Abbreviations}

SARS-CoV-2: Severe Acute Respiratory Syndrome Coronavirus-2; AIHA: Auto Immune Hemolytic Anaemia; RT-PCR: Real-time Reverse Transcription Polymerase
Chain Reaction; Hb: Haemoglobin; MCV: Mean Corpuscular Volume; LDH: Lactate Dehydrogenase; CRP: C-Reactive Protein; ECG: Electrocardiogram; IgG: Immunoglobulin G; IgM: Immunoglobulin M; EBV: Ebstein-Barr Virus; CMV: Cytomegalovirus; HIV: Human Immunodeficiency Virus; ANA: Anti-Nuclear Antibody, USS: Ultra Sound Scan; AKI: Acute Kidney Injury; HTLV-1: Human T-cell Lymphotropic Virus

\section{Introduction}

The number of Coronavirus disease-19 (COVID-19) infected patients is rapidly increasing across the world and the underlying pathophysiology of severe COVID-19 remains poorly understood. According to the published data, it is stated that COVID-19 not only affects the lungs but also various other systems. Circulatory, haematological, and immune systems are three of them [1-3].

Although there have been few reported cases of autoimmune haemolytic anaemia (AIHA) associated with COVID-19 infection, the relationship between this viral infection and AlHA has not been well elucidated $[4,5]$.

Here we are reporting a case of AlHA in a patient with COVID-19 infection. To the best of our knowledge, this is the first Sri Lankan description of an AlHA associated with this viral infection.

\section{Case Presentation}

A 50-year-old previously healthy male was admitted

Citation: Kumarihamy P, Gunaratne S, Ratnayake A, Abeysinghe H, Perera S, et al. (2021) A Case of COVID-19 Infection Associated with Severe Cold Agglutinin Autoimmune Haemolytic Anaemia. Clin Med Rev Case Rep 8:358. doi.org/10.23937/2378-3656/1410358

Accepted: July 29, 2021: Published: July 31, 2021

Copyright: () 2021 Kumarihamy P, et al. This is an open-access article distributed under the terms of the Creative Commons Attribution License, which permits unrestricted use, distribution, and reproduction in any medium, provided the original author and source are credited. 
with a five days' history of fever, cough, and shortness of breath to a tertiary care centre. On the day of admission, he noticed tea-colored urine and worsening of shortness of breath on exertion which gradually progressed to shortness of breath at rest over the next few days. His SARS-CoV-2 RT-PCR test was positive with a Ct value of $26 / 23$. He was transferred to our hospital for specialized COVID-19 treatment on the fifth day of admission to a tertiary care centre. On admission to us (on the $10^{\text {th }}$ day of illness), he complained of shortness of breath at rest and denied any history of bleeding, abdominal pain, or vomiting. There was no past history or family history of haemolytic anaemia. He was severely pale and icteric and had tea-colored urine (Figure 1). He was tachypneic with a respiratory rate of 34 , tachycardic (pulse rate $126)$, and hypoxemic with a saturation of $88 \%$ on room air which was improved to $95 \%$ on $60 \%$ oxygen via venture mask. His blood pressure was $130 / 80 \mathrm{mmhg}$.

Blood results during our hospital stay (from day

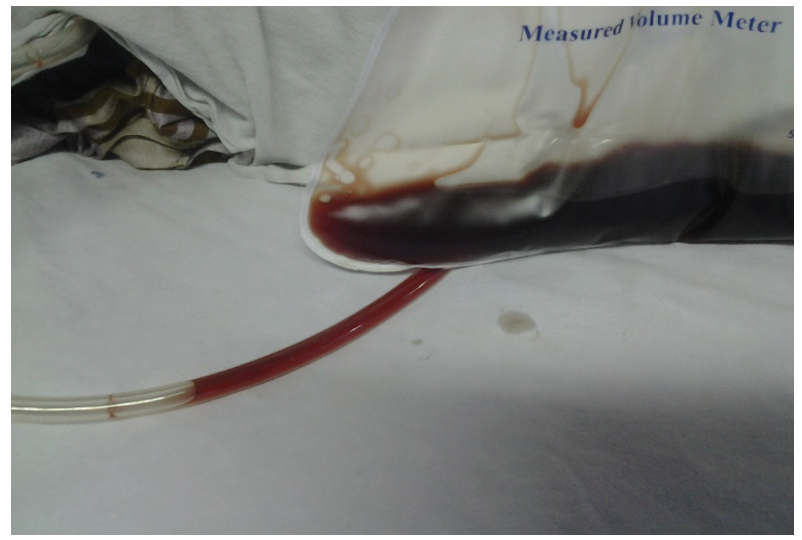

Figure 1: Showing tea color urine.
10 onwards) are shown in Table 1 . His Hemoglobin $(\mathrm{Hb})$ level was $4.5 \mathrm{~g} / \mathrm{dl}$ which was $10.5 \mathrm{~g} / \mathrm{dl}$ four days before. MCV level was $91 \mathrm{fL}(80-100 \mathrm{fL})$. On further investigation, he had laboratory findings suggestive of hemolytic anemia with indirect hyperbilirubinemia and elevated LDH level of $3265 \mathrm{U} / \mathrm{L}$. His venous blood gas analysis showed lactate of $8.3 \mathrm{mmol} / \mathrm{L}$. He had CRP of $179 \mathrm{mg} / \mathrm{dL}$ (Normal < 6), Procalcitonin level of 7.32 ( $<0.5$ sepsis unlikely) and D-dimer level of 8.52 $\mathrm{mg} / \mathrm{L}$ (Normal < 0.5). Troponin I was normal and ECG showed sinus tachycardia. Blood picture (Figure 2) showed normochromic, normocytic red cells with many micro-spherocytes with few red cells agglutination, moderate polychromasia, and NRBCs. There was

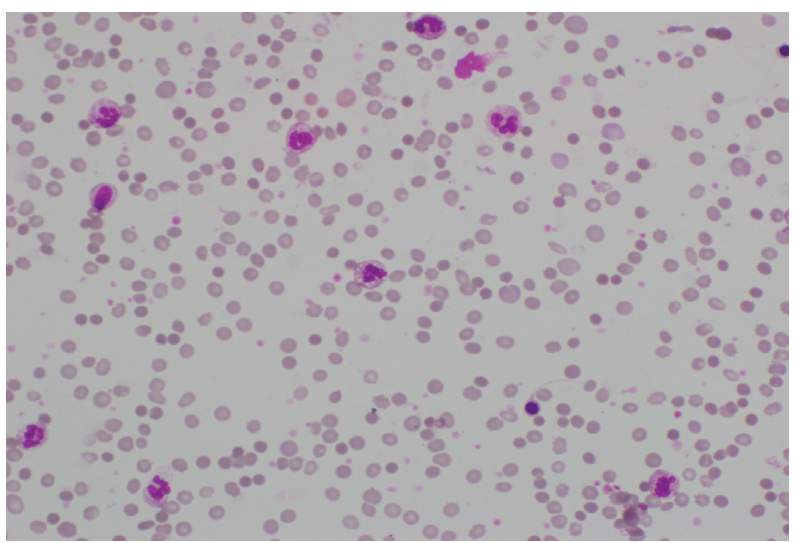

Figure 2: Blood picture showing normochromic, normocytic red cells with many micro-spherocytes with few red cells agglutination, moderate polychromasia, and NRBCs. There is neutrophil leukocytosis with neutrophil left shift up to myelocytes with neutrophils with toxic changes. There is mild thrombocytosis and no atypical cells are seen.

Table 1: Showing laboratory findings from day 10 onwards.

\begin{tabular}{|c|c|c|c|c|c|c|}
\hline & Day 10 & Day 11 & Day 14 & Day 16 & $\begin{array}{l}\text { After } \\
\text { Discharge }\end{array}$ & Normal Range \\
\hline $\begin{array}{l}\text { Hemoglobin } \\
\text { g/dl }\end{array}$ & 4.5 & 6.3 & 8.6 & 9.6 & 10.8 & $12.0-16.0$ \\
\hline $\begin{array}{l}\text { WBC } \\
\times 10^{9} / \mathrm{L}\end{array}$ & 61.52 & 58.25 & 18.04 & 7.18 & 6.51 & $4.00-10.00$ \\
\hline $\begin{array}{l}\text { Neutrophils } \\
\%\end{array}$ & 76.8 & 46.6 & 77.5 & 79 & 4.3 & $50-70$ \\
\hline $\begin{array}{l}\text { Lymphocytes } \\
\%\end{array}$ & 17.3 & 8.5 & 14.8 & 9.8 & 1.37 & $20-40$ \\
\hline $\begin{array}{l}\text { Platelets } \\
\times 10^{9} / \mathrm{L}\end{array}$ & 448 & 372 & 200 & 114 & 110 & $150-450$ \\
\hline $\begin{array}{l}\text { Total bilirubin } \\
\mathrm{mg} / \mathrm{dl}\end{array}$ & 14.2 & 11.44 & 5.43 & 3.52 & & $0.00-2.00$ \\
\hline $\begin{array}{l}\text { LDH } \\
\text { U/L }\end{array}$ & 3265 & & & 1391 & & $140-280$ \\
\hline $\begin{array}{l}\text { Serum Creatinine } \\
\mathrm{mg} / \mathrm{dl}\end{array}$ & 1.26 & 2.70 & 6.14 & 7.39 & & $0.70-1.30$ \\
\hline
\end{tabular}




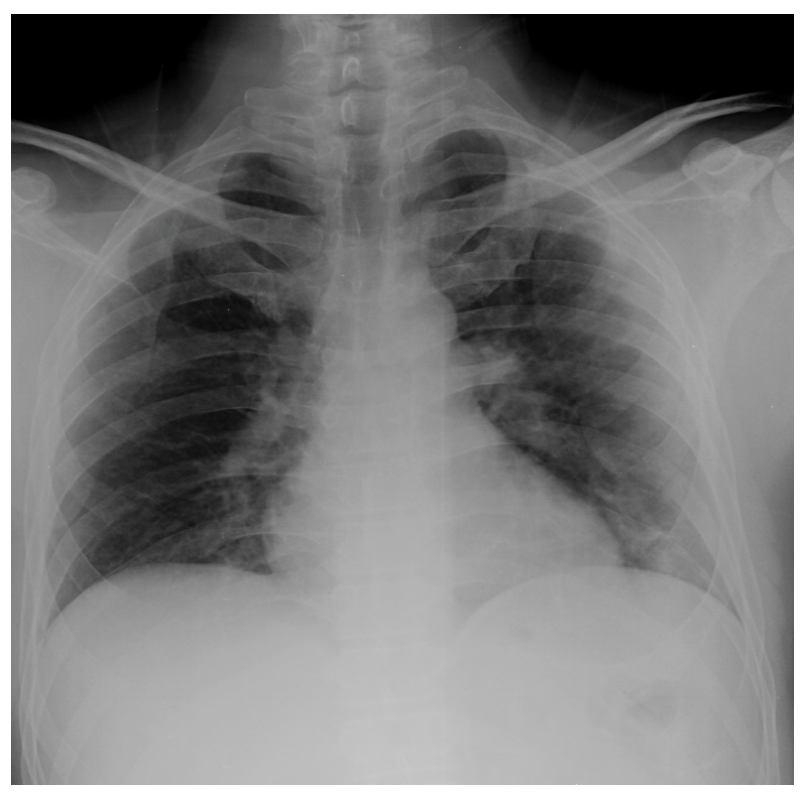

Figure 3: Chest X-ray showing Left lower zonal inflammatory shadows.

neutrophil leukocytosis with neutrophil left shift up to myelocytes with neutrophils with toxic changes. There was mild thrombocytosis and no atypical cells were seen. This was suggestive of haemolytic anaemia. Direct agglutination test was positive with negative anti IgG with positive anti $\mathrm{C} 3 \mathrm{~d}(2+)$. His routine cross-match was incompatible which was corrected in strict $37^{\circ} \mathrm{C}$ (blood group- $A B+$ ). His Creatinine was $0.9 \mathrm{mg} / \mathrm{dl}$ (Normal 0.7$1.3 \mathrm{mg} / \mathrm{dl}$ ) on day six and developed Acute Kidney Injury (AKI) by day 12 with a Creatinine level of $2.7 \mathrm{~g} / \mathrm{dL}$. There was no proteinuria. His Dengue NS-1 antigen, Dengue $\lg M$, and IgG antibodies were negative. Hepatitis $A$ IgM antibody, Hepatitis B surface antigen, Hepatitis C antibody, HIV antigen $1 \& 2$ were negative. Mycoplasma and Cytomegalovirus antibodies were also negative. His ANA was negative. Ultra sound scan (USS) abdomen was normal with no ultrasound evidence of abdominal sepsis and had normal-sized kidneys. USS duplex of bilateral lower limbs was normal. Chest X-ray (Figure 3) showed Left lower zonal inflammatory shadows.

The diagnosis of cold AlHA was made considering blood picture evidence, biochemical evidence of haemolysis, and DAT findings.

He was resuscitated with intravenous normal saline and blood transfusion. A total of five pints of warm blood were given ( 3 pints on the day of admission to our hospital and once daily on the next two days). Intravenous Ceftriaxone $1 \mathrm{~g}$ was given twice daily for seven days. Folic acid $5 \mathrm{mg}$ daily and renal dose of prophylactic Enoxaparin was given along with intravenous Dexamethasone $6 \mathrm{mg}$ daily as per Sri Lankan guidelines in treating COVID-19 pneumonia with hypoxia. His rate of haemolysis gradually declined and had stable hemoglobin by day four of admission to us. However, he had persistently elevated Serum Creatinine and therefore was referred for nephrology follow-up.

He was discharged home on day 17 of his illness and is under nephrology follow-up for renal involvement. One month after the discharge he had hemoglobin of $10.8 \mathrm{~g} / \mathrm{dl}$, total bilirubin of $0.99 \mathrm{mg} / \mathrm{dl}$ (Normal 0.00$2.00)$, and creatinine of $4.11 \mathrm{mg} / \mathrm{dl}$.

\section{Discussion}

COVID-19 is known to cause autoimmune manifestations similar to many other viruses such as EBV, CMV, HIV, and HTLV-1 [6]. The ability of SARSCoV-2 to hyper-stimulate the immune system, induce excessive neutrophil extracellular trap formation with neutrophil-associated cytokine response and the molecular resemblance between host and viral components are described as principal mechanisms causing autoimmunity [6]. Previous reports have revealed both warm and cold agglutinin autoimmune hemolytic anemia associated with COVID-19 [7]. Cold hemagglutinin disease is caused by autoantibodies (usually IgM) against RBC antigens that lead to hemolysis at less than physiological temperature $[8,9]$.

Our patient, who presented with confirmed SARSCoV-2 infection developed severe anemia, jaundice, and tea-colored urine suggestive of hemolysis. After being extensively investigated, a diagnosis of cold agglutinin hemolytic anemia was made. AlHA is associated with infections, lymphoproliferative neoplasms, autoimmune diseases, immune deficiencies, and certain medications etc. $[10,11]$. Our patient did not have a significant past medical history or investigation findings compatible with any of the above causes. His Mycoplasma IgM was also negative, which is a common cause of cold agglutinin hemolytic anemia $[11,12]$. Further Hepatitis A, B, C, Dengue, retroviral, and cytomegalovirus screening were negative. Hence, COVID-19 infection was concluded as the cause for cold agglutinin hemolytic anemia. However, he was not fully evaluated to exclude underlying hematological malignancy.

Currently, there is no evidence-based therapy for secondary cold agglutinin disease in Covid 19 patients, and treatments are mainly based on previous case reports and clinical experiences [7]. Previous reports have documented the successful use of corticosteroids, rituximab, and red cell transfusions $[5,7,13]$. Another report also describes the successful treatment of cold hemolysis with plasma exchange [7]. Our patient was successfully treated with blood transfusions. He also received Dexamethasone $6 \mathrm{mg}$ for 10 days as recommended for treating COVID-19 pneumonia [14]. It can be assumed that steroid therapy might have contributed to hold the hemolysis as well.

Both COVID-19 and AIHA may result in a hypercoagulable state, increasing the risk of both arterial and venous thromboembolism $[15,16]$. Whether AlHA patients benefit from antithrombotic prophylaxis 
remains unresolved [15]. However, this patient received a prophylactic dose of enoxaparin though he did not develop any thromboembolic complications.

This patientalso developed AKIduring thecourse of the disease. The most probable cause for AKI was identified as AlHA-related hemoglobin cast nephropathy. Excessive intravascular hemolysis resulting in hemoglobinuria and acute tubular injury due to toxic metabolites contribute to the pathophysiology [17-19]. However, AKI can also occur as a consequence of COVID-19 (Incidence- 0.9\%$29 \%)$. Direct virulence of SARS-CoV-2 virus on the renal tubular epithelium and podocytes and secondary insults such as hypoxia, cytokine storm, secondary infection with bacteria, other viruses, fungi, and drug-associated nephrotoxicity are all known to contribute to AKI [20]. As serum creatinine remained elevated in this patient, he was referred for nephrology follow-up. Currently, data related to COVID-19 associated renal injury is lacking and therefore requires further evaluation [20].

Although uncommon, COVID-19 associated cold agglutinin haemolytic anaemia can increase the severity of the disease. Such patients have to undergo extensive diagnostic workup to exclude other secondary causes of AlHA to arrive at a definitive diagnosis. Clinicians have to be aware of associated complications including AKI as well. According to our experience red cell transfusion and corticosteroids can be recommended for the treatment of cold agglutinin disease associated with COVID-19. Various treatment modalities and their effectiveness need to be further evaluated.

\section{Declarations}

\section{Ethics approval and consent to participate}

Not applicable.

\section{Consent for publication}

Written informed consent was obtained from the patient for publication of this case report and any accompanying images.

\section{Availability of data and materials}

Not applicable.

\section{Competing interests}

The authors declare that they have no competing interests.

\section{Acknowledgments}

We all express our gratitude to the patient who kindly gave consent for publishing his case in this paper.

\section{Funding}

None.

\section{Author's Contribution}

All authors have equal contribution in this case series. All authors were involved in the management of the patient and read and approved the final manuscript.

\section{References}

1. Huang C, Wang Y, Li X, Ren L, Zhao J, et al. (2020) Articles clinical features of patients infected with 2019 novel coronavirus in Wuhan, China. Lancet 395: 497-506.

2. Thachil J, Tang N, Gando S, Falanga A, Cattaneo M, et al. (2020) ISTH interim guidance on recognition and management of coagulopathy in COVID-19. J Thromb Haemost 18: 1023-1026.

3. Wiggill TM, Mayne ES, Vaughan JL, Louw S (2021) Overview of the haematological effects of COVID-19 infection. Adv Exp Med Biol 1321: 163-172.

4. Saini A, Shayani K, Schwartz J (2021) Cold agglutinin hemolytic anemia induced by COVID-19. American Journal of Medical Case Reports 9: 328-330.

5. Lopez C, Kim J, Pandey A, Huang T, DeLoughery TG (2020) Simultaneous onset of COVID-19 and autoimmune haemolyticanaemia. Br J Haematol 190: 31-32.

6. Dotan A, Muller S, Kanduc D, David P, Halpert G, et al. (2021) The SARS-CoV-2 as an instrumental trigger of autoimmunity. Autoimmun Rev 20: 102792.

7. Ramos-Ruperto L, García-Pérez E, Hernández-Maraver D, Kerguelén-Fuentes A, Viejo-Llorente A, et al. (2021) A 3-case series of autoimmune haemolyticanaemia and COVID-19: Is plasma exchange an alternative? SN Compr Clin Med: 1-4.

8. Jensen CE, Wilson S, Thombare A, Weiss S, Ma A (2020) Cold agglutinin syndrome as a complication of Covid-19 in two cases. Clin Infect Pract 7: 100041.

9. Hill QA, Stamps R, Massey E, Grainger JD, Provan D, et al. (2017) The diagnosis and management of primary autoimmune haemolyticanaemia. Br J Haematol 176: 395411.

10. Zagorski E, Pawar T, Rahimian S, Forman D (2020) Cold agglutinin autoimmune haemolyticanaemia associated with novel coronavirus (COVID-19). Br J Haematol 190: e183-e184.

11. Jacobs J, Eichbaum Q (2021) COVID-19 associated with severe autoimmune hemolytic anemia. Transfusion 61: 635-640.

12. Jawed M, Hart E, Saeed M (2020) Haemolyticanaemia: A consequence of COVID-19. BMJ Case Rep 13: 238118.

13. Barcellini W, Giannotta JA, Fattizzo B (2021) Are patients with autoimmune cytopenias at higher risk of COVID-19 pneumonia? The experience of a reference center in northern Italy and review of the literature. Front Immunol 11: 609198.

14. Rochwerg B, Agarwal A, Ac Siemieniuk R, Agoritsas $T$, Lamontagne $F$, et al. (2020) A living WHO guideline on drugs for covid-19. BMJ 370: m3379.

15. Ruggeri M, Rodeghiero $\mathrm{F}$ (2016) Thrombotic risk in patients with immune haemolyticanaemia. Br J Haematol 172: 144146.

16. Bertoletti L, Couturaud F, Montani D, Parent F, Sanchez O (2020) Venous thromboembolism and COVID-19. Respir Med Res 78: 100759.

17. Nascimento L, Valize P, Cardoso L, Nascimento A (2017) Autoimmune hemolytic anemia and acute kidney injury associated with mycoplasma pneumoniae infection. Residência Pediátrica 6: 87-90. 
18. Perazella MA, Juncos LA, Allon M (2020) Clinical images in nephrology and dialysis. Kidney360 1: 5.

19. Dvanajscak Z, Walker PD, Cossey LN, Messias NC, Boils $\mathrm{CL}$, et al. (2019) Hemolysis-associated hemoglobin cast nephropathy results from a range of clinicopathologic disorders. Kidney Int 96: 1400-1407.

20. Su H, Yang M, Wan C, Yi L-X, Tang F, et al. (2020) Renal histopathological analysis of 26 postmortem findings of patients with COVID-19 in China. Kidney Int 98: 219-227. 